\title{
La experiencia del pasado ante los conflictos actuales
}

\author{
Mercè Gracia | Universitat de Barcelona
}

URL de la contribución <www.iaph.es/revistaph/index.php/revistaph/article/view/4111>

Después de tantos conflictos pasados y tanto patrimonio perdido, en la actualidad no parece que la destrucción del patrimonio se detenga como así lo demuestra el reciente conflicto de Siria. Ni la indignación mundial generada por esta conflagración ni las acciones que lleva a cabo la Organización de las Naciones Unidas para la Educación, la Ciencia y la Cultura (UNESCO) para preservar el patrimonio en peligro parecen ser efectivas. Esta estrategia bélica ya viene de muy lejos, ya en el siglo I a. de C. la Biblioteca de Alejandría fue destruida por las tropas de Julio César. La Revolución Francesa, la guerra civil española o la política nazi también causaron grandes estragos en los bienes históricos y artísticos.

El patrimonio cultural, tanto el material como el inmaterial, entendido como símbolo de la memoria colectiva, ha llegado a ser el foco de la atención de la violencia y una fuente de discordia (CHILTON; SILBERMAN, 2010: 6).

En este sentido, Brodie (2003: 10) hace una revisión crítica de la destrucción y utilización del patrimonio cultural en los períodos de conflicto desde diversas consideraciones y desde una perspectiva actual, estableciendo una clasificación de la destrucción según tres tipologías: como daños colaterales; como objeto de botín de guerra o de expolio intencionado con ánimo de lucro; y como objetivo militar o destrucciones deliberadas a monumentos u objetos artísticos o históricos con una simbología específica, sea religiosa o cultural, con el solo objetivo de "borrar la huella que representa el objeto entendido como símbolo de una determinada cultura, ideología o religión". A las consideraciones de Brodie, se podría añadir el uso político del patrimonio cultural en períodos de conflicto como una cuarta tipología, en el sentido de que el objeto patrimonial se transforma en una herramienta política al servicio del poder dominante del momento poniendo de manifiesto su carácter simbólico, lo que puede provocar su destrucción.
Todos estos aspectos nos darían alguna respuesta a la hora de intentar entender el porqué de la destrucción del patrimonio cultural en el sí de las guerras. De hecho coinciden en los enfrentamientos bélicos pasados y actuales. Podemos citar numerosos ejemplos. Dejando un lado la guerra civil española o las dos guerras mundiales como casos claros en el pasado, y dando un salto en el tiempo, encontramos conflictos como el de Afganistán, donde se aprovechó la destrucción del Museo Nacional de Kabul (1992) para expoliarlo con el objetivo, según Lee (2000: 31), de vender las piezas para la reinversión en el conflicto. Otros ejemplos los encontramos en Camboya o la antigua Yugoslavia con la destrucción intencionada de bienes patrimoniales como edificios, puentes, monumentos históricos y religiosos de todas las creencias. En la misma línea encontramos el caso de los Budas de Bamiyán (2001), que conmocionó a la opinión internacional y generó muchas reacciones dentro de todos los ámbitos, por el enfrentamiento entre los que consideraban la necesidad de preservar el patrimonio y entre aquellos que veían el patrimonio como un elemento a destruir. Fueron destruidos por su significado simbólico, pero sobre todo porque fueron reconocidos como lugares patrimoniales por la comunidad internacional, con la que sus destructores estaban violentamente enfrentados (VIEJO-ROSE, 2011: 54-56). La invasión estadounidense de Irak, en el 2003, supuso la desaparición de miles de piezas del Museo Arqueológico de Bagdad. Algunas de ellas han sido encontradas en manos privadas (POLO, 2006: 67-71).

Otros ejemplos más recientes son los del Museo de Egipto, en enero de 2011, que como consecuencia de una guerra sufrió el pillaje y la destrucción de algunas de sus piezas; el minarete de una de las más famosas mezquitas de Siria del siglo VIII, en la ciudad de Alepo, en este caso su destrucción fue considerada un daño colateral; o la destrucción intencionada del templo de Bel en 


\begin{abstract}
a debate Patrimonio, terrorismo y desastres naturales ¿Cómo prevenir y abordar los enormes daños al patrimonio cultural mundial?
\end{abstract}

| coordinan Francisco Javier López Morales, Francisco Vidargas

la ciudad de Palmira por Estado islámico, en agosto de 2015, considerado por la UNESCO como un crimen de guerra.

Ante tanta devastación, habría que preguntarse, por otra parte, hasta qué punto los acuerdos internacionales han sido efectivos en la preservación del patrimonio artístico y cultural durante los períodos de conflicto. Desde un enfoque normativo general, la UNESCO se preocupó por la defensa del patrimonio cultural. Aunque las convenciones de La Haya de 1899 y de 1907 ya contemplaban normativas de protección de patrimonio a nivel internacional, fue a partir de la Primera Guerra Mundial que se puso de manifiesto que habían quedado obsoletas y se necesitaba una revisión de los principios internacionales en materia de protección de patrimonio cultural, es, pues, en este periodo cuando comenzaron los esfuerzos para la protección del patrimonio a nivel internacional. Pero, a pesar de la existencia de la Convención de La Haya de 1907 y otras normativas internacionales que incidieron en la salvaguarda durante la guerra civil española y la Segunda Guerra Mundial, la destrucción no se detuvo. No fue hasta después de este último conflicto que se creó un protocolo para la protección de los bienes culturales en caso de conflicto armado.

Sin embargo, pasó lo mismo con los acuerdos tomados en La Haya en 1954 sobre la protección de los bienes culturales en caso de conflicto armado y los protocolos que se ratificaron (el segundo de 1999): la destrucción del patrimonio siguió y, por ejemplo, siendo la antigua Yugoslavia uno de los estado miembros de la Convención, nada impidió la destrucción de este estado en los años noventa del siglo pasado. Esto demuestra que no siempre la legislación internacional en materia de protección es efectiva.

El Estatuto de Roma de 2002 y la Corte Penal Internacional (CPI) siguieron contribuyendo a la regulación de la protección del patrimonio cultural en períodos de conflicto. Según su artículo $8^{\circ}$, el estatuto califica la destrucción del patrimonio como crimen de guerra: "Dirigir intencionalmente ataques contra edificios dedi- cados a la religión, la educación, las artes, las ciencias o la beneficencia, los monumentos históricos, hospitales y los lugares donde se agrupan los enfermos y heridos, siempre que no sean objetivos militares " (VON HABSBURG; DESMARAIS, 2014: 26-27). Esta última frase puede resultar ambigua, dado que quién determina que un hospital, escuela o museo puedan ser considerados objetivos militares. Esto permite justificar los incumplimientos legales que se han realizado o que se realizan sobre el patrimonio.

Aunque, en 2011, ICOM ponía de manifiesto su preocupación sobre los últimos conflictos bélicos, en especial los de Túnez, Egipto y Libia, y se reiteraba en su compromiso para preservar y proteger el patrimonio cultural mundial, a la vez que elaboraba y publicaba listas oficiales de los objetos desaparecidos o dañados, los conflictos continúan, y continúan destruyendo el patrimonio cultural de las diferentes comunidades, sin tener presente que con la desaparición de estos bienes desaparece parte de la historia y de la identidad de un pueblo, a veces irrecuperable. Quizás, cabría plantearse por parte de estamentos oficiales, museos e instituciones internacionales nuevos mecanismos de control que permitan implementar políticas efectivas de actuación y protección del patrimonio cultural.

Al final del largo itinerario que conlleva la historia de la destrucción del patrimonio cultural, nos damos cuenta de cómo, de alguna manera, la investigación sobre el pasado se hace presente en el "presente". La guerra de Siria y la destrucción y expolio del patrimonio pone sobre la mesa cómo muchas de las tragedias del pasado vuelven a darse de forma similar en la actualidad. El patrimonio se ve así como un símbolo de los bandos en lucha, como un terreno de confrontación, como un objetivo militar. Su preservación se convierte en un elemento fundamental de las políticas internacionales, pero siempre que hayan guerras los patrimonios -como las vidas humanas- sufrirán las consecuencias. 
_a debate Patrimonio, terrorismo y desastres naturales ¿Cómo prevenir y abordar los enormes daños al patrimonio cultural mundial?

| coordinan Francisco Javier López Morales, Francisco Vidargas

\section{BIBLIOGRAFÍA}

- BRODIE, N. (2003) Historia robada: saqueo y comercio ilícito. Frente a la Historia y el patrimonio en los periodos de conflicto y post-conflicto. Museum Internacional, n. ${ }^{\circ} 219-220$, 2003, pp. $10-25$

- CHILTON, E.; SILBERMAN, N. (2010) Heritage in Conflict and Consensus: towards an international agenda for the twenty-first century. Shared Heritage Shared Futures. Museum international, n. ${ }^{0}$ 245-246, 2010, pp. 6-8

- ICOM (2011) El ICOM y el Escudo Azul intervienen en el Norte de África Boletín [en línea], n. ${ }^{\circ} 4,2011$, p. 2 <https:// www.icom-ce.org/el-icom-y-el-escudo-azul-intervienen-en-elnorte-de-africa/> [Consulta: 16/06/2011]

- LEE, D. (2000) History and art are being wiped out. Art Newspaper, n. ${ }^{\circ} 101,2000$, p. 31

- POLO, H. (2006) Museos de Guerra. El Viejo Topo, n. ${ }^{\circ} 221$, 2006, pp. 67-71

- UNESCO <https://es.unesco.org/> [Consulta: 10/12/2013]

- URUEÑA, R. (2004) La protección del patrimonio cultural en tiempo de guerra y de paz. Cuadernos de Estudios Empresariales, n. ${ }^{\circ} 14,2004$, pp. $245-260$

- VIEJO-ROSE, D. (2011) Destruction and reconstruction of Heritage Impacts on Memory and Identity. En ANHEIER, H.; RAJ ISAR (ed.) Heritage, Memory \& Identity. London: SAGE, 2011, pp. 53-62

- VON HABSBURG, K.; DESMARAIS, F. (2014) La Convención de la Haya: 60 años después. Noticias del ICOM, vol. $67, n^{\circ} .1-2,2014$, pp. 26-27 